\title{
How Blended Learning Reduces Underachievement in Higher Education: An Experience in Teaching Computer Sciences
}

\author{
Fernando Alonso, Member, IEEE, Daniel Manrique, Loïc Martínez, and José M. Viñespartner
}

\begin{abstract}
This paper presents a blended learning approach and a study evaluating instruction in a software engineering-related course unit as part of an undergraduate engineering degree program in computing. In the past, the course unit had a lecture-based format. In view of student underachievement and the high course unit dropout rate, a distance-learning system was deployed, where students were allowed to choose between a distance-learning approach driven by a moderate constructivist instructional model or a blended-learning approach. The results of this experience are presented, with the aim of showing the effectiveness of the teaching/learning system deployed compared to the lecture-based system previously in place. The grades earned by students under the new system, following the distance-learning and blended-learning courses, are compared statistically to the grades attained in earlier years in the traditional face-to-face classroom (lecture-based) learning.
\end{abstract}

Index Terms-Blended learning, computer science education, educational technology, e-learning, moderate constructivism.

\section{INTRODUCTION}

$\mathbf{O}$ VER recent years, there has been a widespread and sharp drop in the participation of, and grades achieved by, undergraduate computing students. For this reason, the Rector's Office at the Technical University of Madrid, Spain, which teaches a number of engineering disciplines, with the support of the management of the School of Computing, which teaches engineering degrees in computing, advocated the use of information and communications technologies to improve student training.

Recent advances in communications technology have led to traditional teaching methods being reconsidered and have caused significant changes in distance teaching [1]. This wealth of technology underpinning e-learning is useless, however, unless attention is paid to the fact that the type of instructional model plays a critical role in technology-enhanced education [2], [3]. There is, therefore, a serious dysfunction between the profusion of technological features that are put forward and the shortage of pedagogical methods and teaching principles for e-learning [4]. Good educational or instructional practice is implemented by the instructional design, which has evolved on a par with the development of the three basic learning theories: behaviorism [5], cognitivism [6], and constructivism [7].

A moderate constructivist e-learning instructional model, which consists of the eclectic combination of these three learning theories and is based on the concept of the learning objective as a set of learning objects [8], has produced good results for teaching computer specialists [9].

This paper presents the experience gathered over the last few years teaching the third-year Program Development Models course unit, which is part of the official five-year engineering degree program in computing. This is an important area of the undergraduate degree programs covered by the Computing Curricula 2005 developed by the Joint Task Force for Computing Curricula formed by the IEEE Computer Society, the Association for Computer Machinery, and the Association for Information Systems [10]. Over the last few academic years (2006-2008), the average grade achieved by students in this course unit was about 4.2-4.4 out of 10 with populations of about 200 students sitting the final examination. In addition to this underachievement, the student dropout rate is high, where between $25 \%$ and $35 \%$ students failed to take the final examination, as they did not consider themselves to be well enough prepared to pass.

Taking the learner's viewpoint, that is, looking at how learning should be staged for the learner optimally to acquire the required knowledge, the chosen educational archetype under the circumstances was a moderate constructivist e-learning instructional model with a blended-learning approach, incorporating psycho-pedagogical prescriptions. A number of specialists in the subject advocate a blended-learning solution [11]-[13], a concept used to describe learning that mixes different activities [14]. The blended approach to the learning process applied in this case combines three ingredients: self-paced learning that provides the right skills at the right time especially in higher education [15]; live e-learning in a virtual classroom where learners can collaborate [16]; and traditional classroom learning, which is necessary to learn management, leadership and collaborative skills [17].

The grades achieved by students in the preceding three years $(2006,2007$, and 2008), where tuition was face-to-face only, 
are also listed. These grades are compared, through a statistical analysis, to student outcomes in the 2009 academic year, where learners were given the chance to take one of two possible different learning/teaching approaches: distance teaching/ learning using a learning management system based on the moderate constructivist instructional model, or the blended-learning approach combining self-paced learning, e-learning, and traditional classroom learning. In all cases, the grades were attained after the completion of a face-to-face examination at the end of the course. Finally, the trend in the student dropout rate, that is to say learners who did not take the final examination over the last four years, is analyzed.

Note that the key aim of this solution, applied in the Program Development Models course unit with considerable success, was to reduce underachievement and also to serve as a pilot experience for deploying the solution in the other subjects that make up the engineering degree in computing. The aim was to attract more students and/or reduce the dropout rate.

\section{Moderate Constructivist E-Learning INSTRUCTIONAL MODEL}

The moderate constructivist instructional model, deployed during the 2009 academic year as part of both the distance teaching/learning option and blended-learning approach, includes prescriptions and methods borrowed from different fields of knowledge. The criteria used to design and implement the educational contents derive from principles based on the content performance matrix [18] and multimedia principles derived from research on information processing psychology within the field of cognitive psychology [19]. These principles further the cognitive processes supported by the memory structures involved in learning.

The educational contents (facts, concepts, procedures, and principles) are structured on the basis of the concept of a learning objective. A learning objective is the specific knowledge that the learner has to acquire about a concept or skill and the tasks to be performed. A learning objective is defined by a set of interrelated learning objects that each deals with a very specific item of knowledge [20]. This structure is useful for developing coherent information structures that help to build knowledge schemata in the learner's mind [21]. A collaborative environment is provided, including activities designed to create a social environment that acts as a scaffold for collaborative learning and dialectical constructivism [22], [23]. This instructional model maps constructivist principles to the instructional design. To do this, it takes a more pragmatic approach that focuses on the principles of moderate constructivism [24], [25], making use of emergent technology tools.

The moderate constructivist e-learning instructional model employed in this blended-learning approach provides the pragmatic level of knowledge defined within Bloom's taxonomy of educational objectives [26] and the performance and action defined by Schulman [27]. Thus, it is based on the fact that training should enable learners to apply the concepts learned at their workplace and evaluate the methods, processes, and tools to be used. To do so, this instructional model applies the systematic development of instruction and learning and is composed of five phases: analysis, design, implementation, execution, and evaluation.

\section{A. Analysis}

This phase defines what to teach. The goal of this phase is to determine learner needs in order to define the right resources and analyze the best-suited educational contents for learners to reach the target knowledge state.

The educational contents are represented as a knowledge graph, denoted as an AND/OR graph whose nodes represent the learning objectives. The arrows that connect these nodes indicate the tasks that have to be completed to achieve a definite knowledge state. AND learning occurs when two or more arrows have the same target node; this indicates that all the source learning objectives need to be acquired before starting on the target learning objective. OR learning occurs when two or more lines are directed at a node; the target learning objective can start to be learned when either of the source learning objectives has been completed.

This phase, then, can establish all the possible knowledge sequences for moving from one initial knowledge state to the course target knowledge state, including all the tasks that the learner has to complete to do this. This way, the proposed model is an objective-driven instructional model with constructivist learning. This model gives the learner the chance to choose, subject to some constraints imposed by the content structure, the next learning objective, following the overarching idea in Ausubel's theory [28].

Fig. 1 shows the knowledge graph for the Program Development Models course unit, which is the focus of this paper. It is composed of 17 learning objectives. A characteristic of this knowledge graph is that it has many OR learning sequences, which gives the learner greater freedom. For example, once learners have achieved the SW Life Cycle learning objective, they have the option of starting either the OO Program Structure or the Procedure + Data Program Structure. On the other hand, there is an AND learning sequence from Object, Class, Message, and Class Relations to attain the Introduction to Unified Process learning objective. Another noteworthy feature of the knowledge graph shown in Fig. 1 is the flexibility that this course unit offers learners: Once learners have completed any of the learning objectives in either of the two branches of the graph (corresponding to development phases in either object-oriented and structured programming paradigms), they can decide whether to learn the next phase in the same paradigm or to learn the equivalent phase in the other paradigm.

\section{B. Design}

The design phase establishes what is to be taught. The learning objectives added to the knowledge graph in the analysis phase are decomposed into learning objects that contain: educational contents, a problem to be solved by a group that covers the concepts described in the educational contents (denoted as being a "good" problem), and evaluation exercises to assess student learning. A good problem is one that requires students to develop cooperative work, can be solved with inexpensive equipment, is realistically complex, benefits from group effort, and is seen as relevant and interesting by 


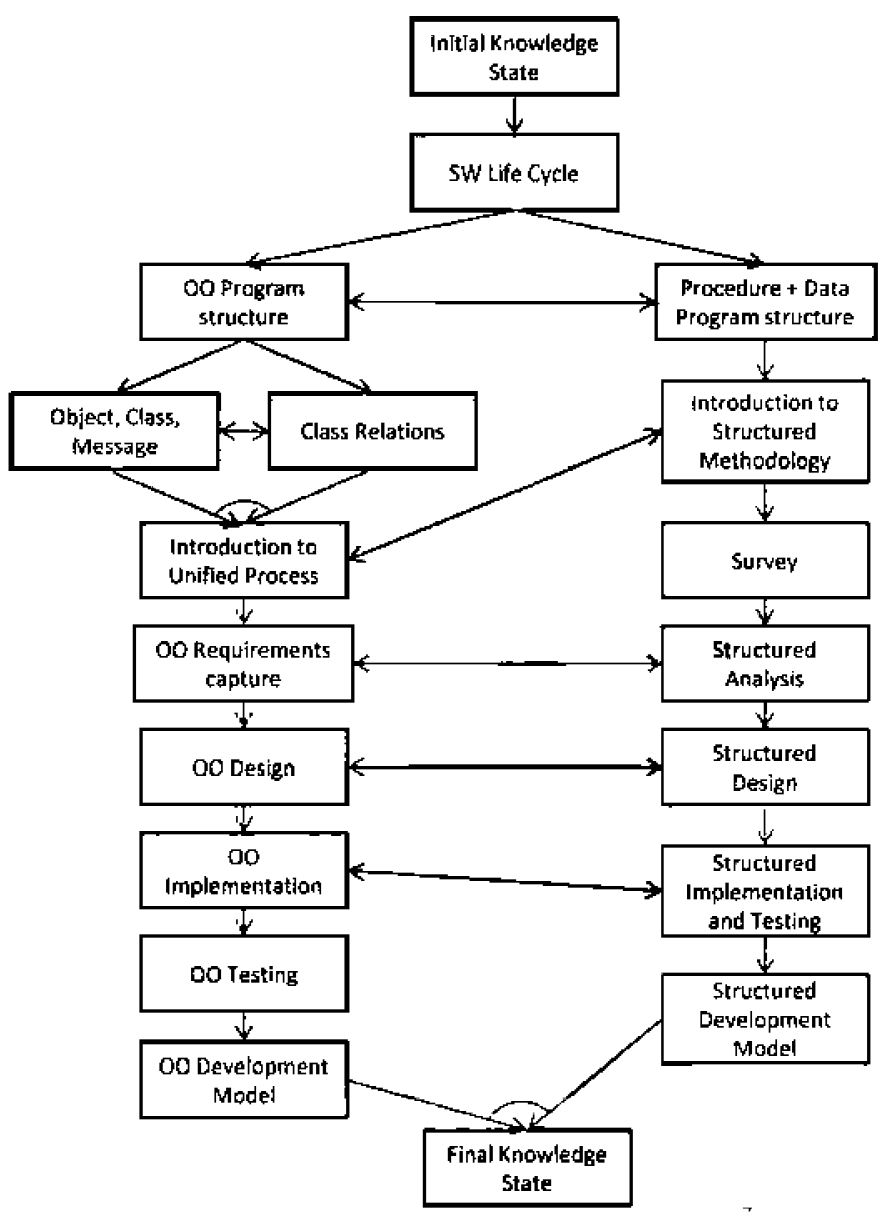

Fig. 1. Program Development Models knowledge graph.

students. Good problems are required to stimulate the exploration and reflection necessary for knowledge construction by learners [29]. Evaluation exercises must also be set to assess what learners have learned. The knowledge state demanded for a learning objective is considered to have been attained when its evaluation exercises have been passed.

This phase establishes the tools, techniques, and environments that are to be used in teaching: hypermedia, multimedia, and the Internet. These improve data gathering and collaboration and offer multiple representations of reality. The design divides contents into five basic types - facts, concepts, processes, procedures, and principles-and two performance outcomes-remember and apply. These two dimensions constitute the content performance matrix that prescribes a template for optimizing learning for each content type.

The learner's learning process is also specified together with the educational activities that will take place within this process, standards to be used, execution criteria, and expected learner outcomes. This learning process is designed by means of a road map. The road map is a graph that represents and interrelates the learning objectives and their learning objects leading to a knowledge state. Therefore, the road map represents the set of all possible paths that go from the initial to the target knowledge state.

The instructor defines and incorporates a good problem and the evaluation exercises for each learning objective. The good problem should account for all the concepts covered by the objects defining the learning objective. Due to the complexity of the whole diagram, Fig. 2 shows a partial road map for the Program Development Models course unit, covering only the following three learning objectives: Object, class, message; Class Relations; and Introduction to the Unified Process. The course knowledge graph shown in Fig. 1 includes all these learning objectives.

One example of a good problem for this subject is that for the Object, class, message learning objective. In this case, learners are asked to read the definition of a system to be developed. They then have to identify candidate classes, objects, and messages. Note that this system definition will be reused across many more good problems, one for each learning objective, although the task to be performed by the learners will be different in each case. The intention is that, at the end of the course, learners will have built the intended system, generating all the required documentation for the different development phases.

\section{Implementation, Execution, and Evaluation}

The implementation phase involves building the road map (educational contents and the learning process) into a learning management system (LMS) platform. To do this, a SCORMcompatible authoring tool was used. In the execution phase, the learner takes the e-learning course. Execution provides information on the problems encountered and the knowledge acquired.

Evaluation determines the success of the course and ascertains the learning product quality. For this purpose, information output during execution is gathered, and the results are analyzed on the basis of the learning objects and objectives. For the educational content learning objects and the good problems, the total time each learner spends on learning an object is stored, and the interaction between learners, and between learners and the instructor, as well as the number of questions formulated by the learner are recorded. Finally, the grades that learners achieve in the evaluation exercises and the total time they spend on learning an objective are stored.

The content expert can analyze this information to find out whether an educational content learning object should be revised-for example, if the mean time spent studying the learning object is significantly higher than originally estimated by the content expert at design time. Similarly, it provides the instructor with statistical data about the execution of the learning objectives, giving clues as to whether any have been poorly designed. From this information, the instructor can draw conclusions about abnormally low grades or there being too much interaction to solve a good problem.

\section{BLENDED-LEARNING APPROACH}

This blended-learning approach to the learning process applies the aforementioned moderate constructivist model and includes three learning types: self-paced learning, live e-learning, and face-to-face classroom learning. Self-paced learning is an asynchronous interactive mode of learning over the Internet. This learning process is represented by the road map developed in the instructional model design phase. Live e-learning is a synchronous process. It is a mode of collaborative learning that can be implemented by means of 


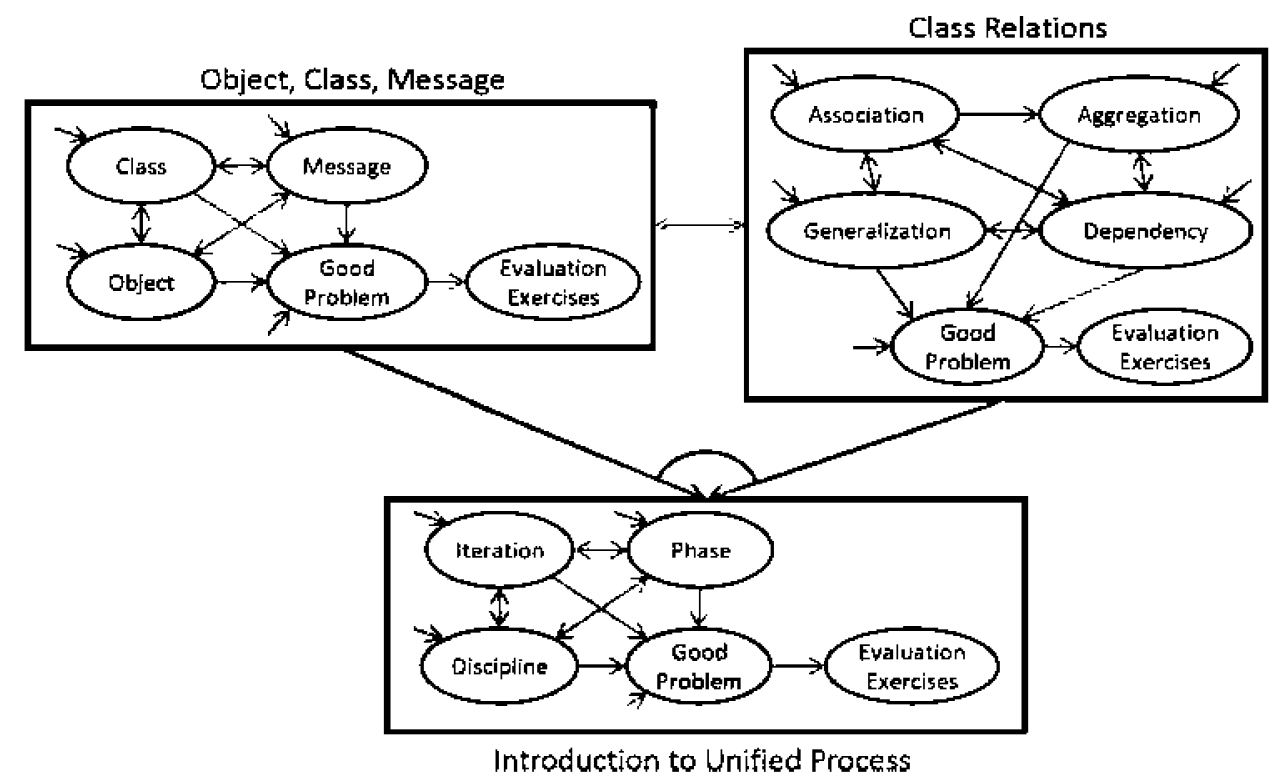

Fig. 2. Fragment of the Program Development Models road map.

videoconferences, threaded discussions, online chats, or virtual classrooms at a scheduled time. Learners collaborate, share information, and ask each other and the instructor questions in real time. The power of combining live e-learning and self-paced learning is augmented dramatically when there is meaningful collaboration. Collaborative learning affords students enormous advantages that more traditional distance learning cannot give because a group can accomplish meaningful learning and solve problems better than any individual can alone. The face-to-face or traditional classroom is the third ingredient of blended learning. Despite its defects, classroom training is still unbeatable in the development of social competencies, for the amount of face-to-face interaction with both the instructor and classmates. This interaction is necessary to learn certain management, leadership, and other highly collaborative skills [17].

This blended learning process consists of a 15 -week course executed as follows.

1) The course kicks off with a one-day face-to-face session where the learners have the chance to meet each other and the instructor. The instructor presents the learning objectives, discusses the most significant knowledge and tasks to be learned, and describes computer-mediated interaction (e-mail, chats, and forums).

2) Every week, there is a 2-h face-to-face session where students ask the instructor questions about the contents they have studied over the last week and discuss problems that they have encountered and possible solutions. The instructor presents the most important contents to be studied over the following week, stressing the concepts that are most important or harder to learn.

3) One-hour interactions between learners and between learners and the instructor are held every week via chat and/or forums to consolidate and acquire knowledge. These sessions are held informally, and their development is not structured. These sessions are especially important for students that were unable to attend the face-to-face session.

4) There is permanent e-mail support, and queries should be answered within $24 \mathrm{~h}$.

5) Face-to-face support is available to students $6 \mathrm{~h}$ a week. Learners can meet the instructor either individually or in groups to clarify contents and receive support on how to solve the good problems.

6) An online assessment is held every week, where the students have to complete a five-question questionnaire.

7) A final face-to-face assessment is held immediately after the course has finished. Students have to sit a 10-question examination, where they will be expected to complete short exercises on a common problem similar to the ones used in the good problems. The examination typically lasts $2.5 \mathrm{~h}$. Learner evaluation takes into account the scores achieved in this test, the solution of the weekly questionnaires, the solutions given to the good problems set throughout the course, and the learner's participation in live e-learning sessions.

\section{STUdy Design}

Because of widespread underachievement and an increase in the dropout rate of students taking the undergraduate engineering degree in computing, this pilot experience was run on the Program Development Models course unit. The goal of the study was to analyze the impact that the deployment of this new learning system has had on the dropout rate and academic achievement of learners taking this course unit. To do this, a statistical analysis was run to compare the grades attained by students throughout the academic year according to the three instructional conditions evaluated: traditional face-to-face classroom learning over the 2006, 2007, and 2008 academic years; and distance learning and blended learning, as options chosen by students and deployed in the 2009 academic year. 
TABLE I

DESCRIPTIVE STATISTICS: DEPENDENT VARIABLE—GRADES

\begin{tabular}{|c|c|c|c|c|c|c|c|c|}
\hline & \multirow[b]{2}{*}{$N$} & \multirow[b]{2}{*}{ Mean } & \multirow[b]{2}{*}{ Std. Dev. } & \multirow[b]{2}{*}{ Std. Firror } & \multicolumn{2}{|c|}{$95 \%$ Confidence Interval for Mean } & \multirow[b]{2}{*}{ Minimum } & \multirow[b]{2}{*}{ Maximum } \\
\hline & & & & & Iower Bound & Upper Bound & & \\
\hline BL-2009 & 55 & 5.07500 & 1.735655 & .234036 & 4.60579 & 5.54421 & 1.250 & 9.000 \\
\hline EI -2009 & 52 & 4.85577 & 1.347516 & .186867 & 4.48062 & 5.23092 & 1.125 & 7.750 \\
\hline FF-2008 & 124 & 4.43972 & 1.636692 & .146979 & 4.14878 & 4.73065 & 1.375 & 9.000 \\
\hline $\mathrm{FF}-2007$ & 198 & 4.21338 & 1.509619 & .107284 & 4.00181 & 4.42496 & .375 & 7.875 \\
\hline ГГ-2006 & 264 & 4.27888 & 1.417254 & .087226 & 4.10713 & 4.45063 & .250 & 8.250 \\
\hline Total & 693 & 4.39542 & 1.524746 & .057920 & 4.28170 & 4.50914 & .250 & 9.000 \\
\hline
\end{tabular}

A total of 693 students were involved in this study. This figure does not include students who dropped out of the subject during the respective academic year or students who only took the final face-to-face assessment at the end of the course. Of these 693 students, 264, 198, and 124 learners received face-to-face tuition over the 2006, 2007, and 2008 academic years, respectively, and the other 107 received instruction during the 2009 academic year. Of these 107 students, 55 opted for a blendedlearning approach, whereas the other 52 enrolled for distance learning. The gender distribution of students in the sample was approximately $81 \%$ male and $19 \%$ female who were, with very few exceptions, of the same ethnicity and of very similar ages, ranging from 20 to 23 years old. The subject was taught by the same two teachers using the three teaching methods.

Instructional condition and academic year served as the independent variable, with five levels: blended learning taught in 2009 (BL-2009), distance learning taught in 2009 (EL-2009), and face-to-face learning taught over the 2008, 2007, and 2006 academic years (FF-2008, FF-2007, and FF-2006, respectively). The criterion measured was the overall course performance, graded from 0 to 10. Each learner experienced only one of the different instructional methodologies, and the subjects had the same background knowledge, as all the students were in the same year of their undergraduate engineering degree in computing course

\section{RESULTS AND DISCUSSION}

The results follow for each of the five values of the independent variable (instructional condition and academic year) applied to the Program Development Models course unit using the samples described previously. Table I shows descriptive statistics for the dependent variable: overall course performance (grades).

An analysis of variance (one-way ANOVA) was conducted to gather empirical evidence of whether the differences between the means are statistically significant. One of the conditions of an ANOVA is that the variances of the groups should be equivalent. ANOVA is robust to this violation when the groups are of equal or near equal size. This does not apply in the sample under study, so a Levene test of homogeneity of variances was run. The results of this test (with degrees of freedom df $1=4$ and $\mathrm{d} f 2=688$ and Levene Statistic 1.749) returned a significance level of $\mathrm{p}<0.137$, which suggests that the homocedasticity
TABLE II

ONE-WAY ANOVA: GRADES

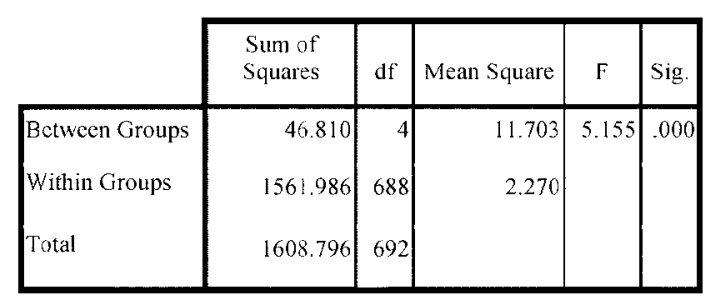

hypothesis cannot be rejected, and it is possible to run the ANOVA.

Table II shows the results of the ANOVA test, showing that the null hypothesis (the mean grades achieved by students in the Program Development Models course unit are equal) can be rejected because of the resulting $\mathrm{F}(\mathrm{df}=4 / 688)$ of 5.155 , $p<0.01$. Thus, the overall course performance achieved by learners depends on the instructional condition and academic year.

As there are sizeable differences between the five groups with respect to the instructional model and academic year, the Tukey HSD test was used to make post hoc comparisons to demonstrate where the statistically significant differences are to be found. Table III shows the significance level for these multiple comparisons, taking into account that the significance level for the mean difference is $p<0.05$. This has been marked in bold and by an asterisk.

Table IV clearly shows the homogeneous subsets that can be built for $\alpha=0.05$, grouping levels of the independent variable that have a similar mean. From Table IV, it is clear that the academic year does not influence overall course performance as there are no significant differences between the students receiving face-to-face tuition during the 2006, 2007, and 2008 academic years. On the other hand, the instructional model does turn out to be influential, as there are statistically significant differences between the blended-learning approach in 2009 and the attainment of students that received traditional tuition in earlier years. Noteworthy again is that there are no pronounced differences between the grades achieved by students taking distance learning (e-learning) and blended learning in 2009. Also, although the mean grade achieved by students in 2009 using the deployed e-learning system appears to be higher $(4.856)$ 
TABLE III

Post Hoc Test: Multiple Comparisons, TuKey HSD Test, DePendent Variable — Grades

\begin{tabular}{|c|c|c|c|c|c|c|}
\hline \multirow{2}{*}{$\begin{array}{l}\text { (I) Instr. Condition } \\
\text { and Year }\end{array}$} & \multirow{2}{*}{$\begin{array}{l}\text { (J) Instr. Condition } \\
\text { and Year }\end{array}$} & \multirow{2}{*}{$\begin{array}{c}\text { Mean } \\
\text { Difference } \\
(1-J)\end{array}$} & \multirow{2}{*}{ Std. Error } & \multirow[t]{2}{*}{ Sig. } & \multicolumn{2}{|c|}{$95 \%$ Confidence Interval } \\
\hline & & & & & Lower Bound & Upper Bound \\
\hline \multirow[t]{4}{*}{ BL-2009 } & EL-2009 & .219231 & .291443 & .944 & -.57787 & 1.01633 \\
\hline & FF- 2008 & .635282 & .244106 & .071 & -.03235 & 1.30292 \\
\hline & FF- 2007 & $.861616^{*}$ & .229663 & .002 & .23348 & 1.48975 \\
\hline & FF- 2006 & $.796117^{*}$ & .223335 & .004 & .18529 & 1.40694 \\
\hline \multirow[t]{4}{*}{ EL-2009 } & BL-2009 & -.219231 & .291443 & .944 & -1.01633 & .57787 \\
\hline & FF-2008 & 416051 & .248936 & .452 & -.26480 & 1.09690 \\
\hline & FF-2007 & $.642385^{*}$ & .234790 & .050 & .00023 & 1.28454 \\
\hline & FF-2006 & .576887 & .228604 & .087 & -.04835 & 1.20213 \\
\hline \multirow[t]{4}{*}{ FF-2008 } & BL-2009 & -.635282 & .244106 & .071 & -1.30292 & .03235 \\
\hline & EL-2009 & -.416051 & .248936 & .452 & -1.09690 & .26480 \\
\hline & FF-2007 & .226334 & .172556 & .684 & -.24561 & .69828 \\
\hline & FF-2006 & .160835 & .164039 & .864 & -.28782 & .60949 \\
\hline \multirow[t]{4}{*}{ FF- 2007} & BL-2009 & $-.861616^{*}$ & .229663 & .002 & -1.48975 & -.23348 \\
\hline & EL-2009 & $-.642385^{*}$ & .234790 & .050 & -1.28454 & -.00023 \\
\hline & FF-2008 & -.226334 & .172556 & .684 & -.69828 & .24561 \\
\hline & FF-2006 & -.065499 & .141655 & .991 & -.45293 & .32193 \\
\hline \multirow[t]{4}{*}{ FF- 2006} & BL-2009 & $-.796117^{*}$ & .223335 & .004 & -1.40694 & -.18529 \\
\hline & EL-2009 & -.576887 & .228604 & .087 & -1.20213 & .04835 \\
\hline & FF-2008 & -.160835 & .164039 & .864 & -.60949 & .28782 \\
\hline & FF-2007 & .065499 & .141655 & .991 & -.32193 & .45293 \\
\hline
\end{tabular}

TABLE IV

Post Hoc Test: Homogeneous Subsets, Tukey HSD Test, Grades

\begin{tabular}{l|r|r|r|r}
\hline Instr. Condition & & \multicolumn{3}{|c}{ Subset for alpha $=0.05$} \\
\cline { 3 - 5 } and Year & $\mathrm{N}$ & 1 & 2 & 3 \\
\hline FF-2007 & 198 & 4.21338 & & \\
FF-2006 & 264 & 4.27888 & 4.27888 & \\
FF-2008 & 124 & 4.43972 & 4.43972 & \\
El -2009 & 52 & & 4.85577 & 4.85577 \\
BL-2009 & 55 & & & 5.07500 \\
Sig. & & .847 & .072 & .861 \\
\hline
\end{tabular}

than for students receiving traditional tuition in all three previous years ( 4.28 in $2006,4.21$ in 2007 , and 4.44 in 2008), there are no significant differences between e-learning in 2009 and face-to-face tuition in 2006 and 2008, as shown in subset 2 of Table IV. Even so, it is worth mentioning that the significance of this subset $(p<0.072)$ is low compared to the high level of significance of the other two subsets $(\mathrm{p}<0.847$ subset 1 , and $\mathrm{p}<0.861$ for subset 3 ).

The view taken here is that e-learning achieves a better score than face-to-face tuition, basically because e-learning is individualized (the student learns through self-study and self-assessment) and cooperative (students have to do group work) in the same way that face-to-face learning can be. However, students can get on with their everyday life, without having to adapt systematically to a specific space and time, as they are obliged to do in face-to-face tuition. This way they have the freedom to study anywhere and anytime. All this motivates the students' interest in the subject, which encourages learning and leads to better outcomes.

Another positive point worth mentioning with respect to the inclusion of the moderate constructivist e-learning instructional model and the blended learning approach in the 2009 academic year is the reduction of the dropout rate. Fig. 3 plots the trend since 2000 . It starts with a high rate of evaluated students taking 
Evaluated learners

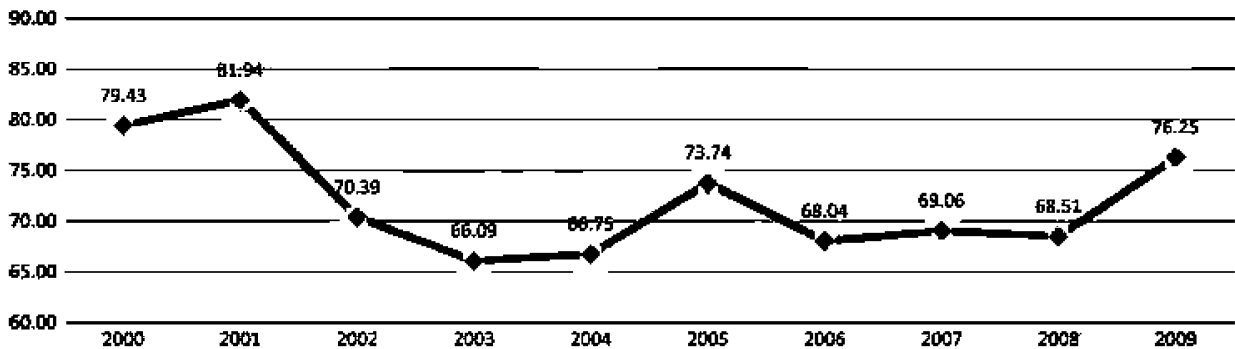

Fig. 3. Evolution of the percentage of evaluated students over enrolled students for the Program Development Models course unit since 2000.

the course unit of around $80 \%$ in the 2000 and 2001 academic years (which is when the course unit was first taught). There was then a sharp drop in 2002 and 2003 to $65 \%-70 \%$, and levels remained unchanged until 2008, with the exception of 2005). In 2009 , however, coinciding with this pilot experience, the percentage of students evaluated rose back up to $75 \%$.

\section{CONCLUSION}

This paper gives empirical evidence that it is possible to reduce underachievement in higher education through an adequate use of e-learning technology, supported by a moderate constructivist instructional model and a blended learning approach. The experiment was run over the 2006-2009 academic years with undergraduate students enrolled in the Program Development Models course unit, which is part of the undergraduate engineering degree in computing taught at the Technical University of Madrid.

There were two factors motivating the experiment: 1) a drop in the percentage of students evaluated over students enrolled; and 2) low student grades. The dropout rate started to rise in 2001 , when approximately $80 \%$ of enrolled students were assessed and remained more or less unchanged from 2003 to 2008, at a mean of $68.70 \%$. The finding was that students achieved statistically similar grades of under 4.5 out of 10 over the 2006 , 2007, and 2008 academic years.

Faced with this situation, the decision was made in 2009 to use e-learning technologies to teach the subject with the aim of motivating students to take the final examination and increase the mean grade attained over the previous years. To do this, students were given the option of choosing between a distance learning (e-learning) option driven by the moderate constructivist instructional model described in this paper or opt for the proposed blended-learning approach including three ingredients: self-paced learning, live e-learning, and face-to-face classroom learning. According to this criterion, two groups were formed in 2009. The groups were homogeneous in terms of size, learning styles, gender distribution, ethnicity, and age to ensure that these parameters did not affect the study results. They were also taught by the same two teachers.

Statistically speaking, the mean grades achieved by students in each of the five groups formed (FF-2006, FF-2007, FF-2008, BL-2009, and EL-2009) can be divided into three categories of similar mean grades: FF-2006, FF-2007, and FF-2008; FF-2006, FF-2008, and EL-2009; and BL-2009 and EL-2009. As of this result, no significant differences are found between the grades achieved by students in the blended-learning and e-learning options. On the other hand, the mean grade for students receiving blended learning in 2009 is statistically greater (5.07) than the mean grade achieved by students receiving traditional tuition in previous years. Another positive point is that there was an increase in the percentage of students who were evaluated with respect to previous years, which reached a level of $76.25 \%$.

The professors were very pleased by the performance of the blended learning approach. However, it is important not to overlook the additional workload involved in this approach compared with traditional teaching.

The good results for this educational innovation experience are thought to be attributable to three reasons. First, the moderate constructivist e-learning instructional model with a blended-learning approach provides more individualized instruction than traditional face-to-face tuition. Second, it enables learners to accommodate the space/time demands of other interests, as students can carry on other everyday activities without having to adapt to strict space/time constraints. Third, students can work cooperatively. Cooperative activities help to promote information exchange flows among students, build up cognitive knowledge construction processes, and strengthen motivational and informal affective bonds of mutual support and friendship. The measurement and assessment of these aspects opens up an interesting research field meriting further investigation. The different interactions (information exchange, cognitive and affective processes) set up networks with structural patterns that determine the effectiveness of the learning processes experienced by learners as individuals and as a group. The analysis of this approach, based on learning through social relations and networks, is expected to help gain a better understanding of learning processes in virtual environments and to improve group dynamics management in such environments.

\section{REFERENCES}

[1] S. R. Jernigan, Y. Fahmy, and G. D. Buckner, "Implementing a remote laboratory experience into a joint engineering degree program: Aerodynamic levitation of a beach ball," IEEE Trans. Educ., vol. 52, no. 2 , pp. 205-213, May 2009.

[2] F. Alonso, G. López, D. Manrique, and J. M. Viñes, "An instructional model for web-based e-learning education with a blended learning process approach," Brit. J. Educ. Technol., vol. 36, no. 2, pp. 217-235, Mar. 2005

[3] B. W. Tuckman, "Evaluating ADAPT: A hybrid instructional model combining web-based and classroom components," Comput. Educ., vol. 39, no. 3, pp. 261-269, Nov. 2002. 
[4] M. K. Tallent-Runnels, W. Y. Lan, W. Fryer, J. A. Thomas, S. Cooper, and $\mathrm{K}$. Wang, "The relationship between problems with technology and graduate students' evaluations of online teaching," Internet High. Educ., vol. 8, no. 2, pp. 167-174, 2005, 2nd qt..

[5] T. L. Good and J. E. Brophy, Educational Psychology: A Realistic Approach, 4th ed. White Plains, NY: Longman, 1990.

[6] N. H. Anderson, A Functional Theory of Cognition. Hillsdale, NJ: Erlbaum, 1996.

[7] D. H. Jonassen, "Objectivism versus constructivism: Do we need a new philosophical paradigm?," Educ. Technol. Res. Dev., vol. 39, no. 3, pp. 5-14, 1991.

[8] L. Anido and J. Santos, "A component model for standardized webbased education," in Proc. 10th Int. World Wide Web Conf., Hong Kong, 2001, pp. 86-95.

[9] F. Alonso, D. Manrique, and J. M. Viñes, "A moderate constructivist e-learning instructional model evaluated on computer specialists," Comput. Educ., vol. 53, no. 1, pp. 57-65, Aug. 2009.

[10] "Computing curricula 2005. The overview report. A volume of the computing curricula series," Joint Task Force for Computing Curricula of IEEE Computer Society, Association for Computing Machinery, and Association for Information Systems, Sep. 2005, .

[11] H. El-Deghaidy and A. Nouby, "Effectiveness of a blended e-learning cooperative approach in Egyptian teacher education programme," Comput. Educ., vol. 51, no. 3, pp. 988-1006, Nov. 2008.

[12] D. R. Garrison and H. Kanuka, "Blended learning: Uncovering its transformative potential in higher education," Internet Higher Educ., vol. 7 , no. 2, pp. 95-105, 2004, 2nd qt..

[13] K. Thorne, Blended Learning: How to Integrate Online and Traditional Learning. Hillsdale, NJ: Kogan Page, 2003.

[14] N. Hoic-Bozic, V. Mornar, and I. Boticki, "A blended learning approach to course design and implementation," IEEE Trans. Educ., vol. 52, no. 1, pp. 19-30, Feb. 2009.

[15] H. J. C. Ellis, "An assessment of a self-directed learning approach in a graduate web application design and development course,"IEEE Trans. Echuc., vol. 50, no. 1, pp. 55-60, Feb. 2007.

[16] G. Stahl, "Group cognition in computer-assisted collaborative learning," J. Comput. Assist. Learn., vol. 21, no. 2, pp. 79-90, Apr. 2005.

[17] L. Michell, "E-Learning methods offer a personalized approach," InfoWorld, pp. 174-185, Apr. 2001.

[18] M. D. Merrill, "Instructional strategies that teach," CBT Solutions, pp. 1-11, Nov.-Dec. 1996

[19] R. Clark, Building Expertise: Cognitive Methods for Training and Performance Improvement. Washington, DC: Int. Soc. Perform. Improvement, 1998.

[20] F. Alonso, G. López, D. Manrique, and F. J. Soriano, "E-learning instructional approach with learning objects," in Proc. 6th WSEAS Int. Conf. E-Activities, Tenerife, Spain, 2007, pp. 242-247.

[21] M. S. Donovan, J. D. Bransford, and J. W. Pellegrino, How People Learn: Bridging Research and Practice. Washington, DC: Nat. Res. Council Committee Learn. Res. Educ. Practice, 1999.

[22] R. Palloff and K. Pratt, Building Learning Communities in $C y$ berspace. Effective Strategies For Online Classroom. San Francisco, CA: Jossey-Bass, 1999.

[23] R. Palloff and K. Pratt, The Virtual Student: A Profile and Guide to Working With Online Learners. San Francisco, CA: Jossey-Bass, 2003.

[24] Y. Karagiorgi and L. Symeou, "Translating Constructivism into instructional design: Potential and limitations," Educ. Technol. Soc., vol. 8, no. 1, pp. $17-27,2005$

[25] L. Moreno, C. Gonzalez, I. Castilla, E. Gonzalez, and J. Sigut, "Applying a constructivist and collaborative methodological approach in engineering education," Comput. Educ., vol. 49, no. 3, pp. 891-915, Nov. 2007.

[26] B. S. Bloom, Taxonomy of Educational Objectives. White Plains, NY: Longman, 1956, Book 1, Cognitive domain.

[27] L. S. Schulman, "Making differences: A table of learning," Change, vol. 34, pp. 36-44, 2002.

[28] D. Ausubel, J. Novak, and H. Hanesian, Educational Psychology: A Cognitive View, 2nd ed. New York: Holt, Rinehart and Winston, 1978.
[29] J. G. Brooks and M. G. Brooks, In Search of Understanding: The Case for Consiructivist Classrooms. Alexandria, VA: Assoc. Supervision Curriculum, 1993.

Fernando Alonso (M'92) received the B.Eng. degree in industrial engineering and the B.S. and Ph.D. degrees in computer science from the Universidad Politécnica de Madrid (UPM), Madrid, Spain, in 1970, 1972, and 1985, respectively.

He is a Full Professor of computer science with the UPM's School of Computer Science, where he has worked as a full-time Professor and Researcher since 1989. He is also the R\&D Director of the Centre of Computing and Communications Technology Transfer (CETTICO) based at the UPM and Director of the UPM's Computer and Communications Technology Research Group. His major field of interest is e-learning (he uses the blended-learning approach for all his undergraduate teaching) and software and knowledge engineering.

Prof. Alonso won a UPM university prize for this Ph.D. dissertation. He received the Best Application Paper Award at the IEEE 2001 International Conference on Data Mining for the paper titled "Discovering Similar Patterns for Characterizing Time Series in a Medical Domain."

Daniel Manrique received the B.S. and $\mathrm{Ph} . \mathrm{D}$. degrees in computer science from the Universidad Politécnica de Madrid (UPM), Madrid, Spain, in 1997 and 2001, respectively.

He is currently an Associate Professor of computing with the UPM's School of Computing, where he is the Academic Secretary of the AI Department. His major fields of study and research are new educational technologies and artificial intelligence, in which he has participated as a researcher in several European or Spanish research projects.

Dr. Manrique is a member of the international program committee of several international congresses and acts as a reviewer of important international journals.

Loïc Martínez received the B.S. and Ph.D. degrees in computer science from the Universidad Politécnica de Madrid (UPM), Madrid, Spain, in 1993 and 2003, respectively.

He is currently an Associate Professor of computing at the UPM's School of Computing. He coordinates a Spanish standardization group on computing accessibility and participates as an expert in international standardization groups specializing in computing ergonomics and user interfaces. His major fields of study and research are accessibility for people with disabilities to information technologies, software development methodologies, and data mining techniques, in which he has participated as a researcher in over 40 European or Spanish research projects.

Dr. Martinez is a member of the international program committee of several international congresses and acts as a reviewer of international journals such as Behaviour \& Information Technology. He received the Best Application Paper Award at the IEEE 2001 International Conference on Data Mining for his paper "Discovering Similar Patterns for Characterizing Time Series in a Medical Domain."

José M. Viñes received the B.Eng. degree in aeronautics engineering from the Universidad Politécnica de Madrid (UPM), Madrid, Spain, in 1972; the B.S. degree in psychology from the Universidad Autónoma de Madrid (UAM), Madrid, Spain, in 1980; the Executive M.B.A. degree from the Instituto Empresa, Madrid, Spain, in 1984; and the Diploma of Advanced Studies in applied creativity from the UAM in 2009.

He is currently a partner of Aulatika S.L.. a Spanish consulting firm in Madrid, Spain, specialized in e-learning design and social network analysis focusing on knowledge management and organizational innovation and creativity. He has lengthy experience in airline technological and psychological human resources management and business management. 